\title{
Study of antidiabetic activities of endophytic fungi isolated from plants
}

\author{
Rimsha Khan ${ }^{1}$, Syeda Tahira Qousain Naqvi ${ }^{1}$, Nighat Fatima ${ }^{2}$ and Syed \\ Aun Muhammad ${ }^{1 *}$ \\ 1. Institute of Molecular Biology and Biotechnology, Bahauddin Zakariya University Multan-Pakistan \\ 2. Department of Pharmacy, COMSATS Institute of Information Technology, Abbottabad-Pakistan \\ *Corresponding author's email: aunmuhammad78@yahoo.com
}

Citation

Rimsha Khan, Syeda Tahira Qousain Naqvi, Nighat Fatima and Syed Aun Muhammad. Study of antidiabetic activities of endophytic fungi isolated from plants. Pure and Applied Biology. Vol. 8, Issue 2, pp1287-1295. http://dx.doi.org/10.19045/bspab.2019.80071

\begin{tabular}{llll}
\hline \hline Received: 08/01/2019 & Revised: 19/04/2019 & Accepted: 22/04/2019 & Online First: 26/04/2019 \\
\hline
\end{tabular}

\section{Abstract}

Diabetes mellitus, a metabolic disorder, is one of the major causes of death among all health issues. Diabetes can be regulated by antidiabetic drugs that control the activity of some metabolic enzymes including amylases. Endophytic fungi have the potential to prevent diabetes through inhibition of alpha-amylase activity. This study was aimed to isolate and evaluate endophytic fungi from different plants like Mango (Mangifera indica) coded as MAN, MBR, Neem (Azadirachta indica) indicated as NGU and NTH and jambolan (Syzygium cumini L) shown as JCO, JGR, JGY for their antidiabetic potentials. Eight endophytic fungi, isolated from the leaves of these plants, were screened for their potential anti-amylase activity. Aqueous extract of endophytic fungi isolated from jambolana $(200 \mu \mathrm{g} / \mathrm{ml})$ exhibited significant amylase inhibition (62\%) followed by MAN, MBR, NGU and NTH sample (49-59\%). Therefore, endophytic fungi from the leaves of selected plants might be remarkable sources of discovering natural anti-diabetic molecules.

Keyword: Azadirachta indica; Diabetes mellitus; Mangifera indica; Syzygium cumini

\section{Introduction}

Diabetes mellitus is a chronic metabolic disease that disturbs the metabolism of carbohydrates, fats, proteins, water and electrolytes [1]. It is a disorder of endocrine system that is responsible for the emergence of a group of various metabolic diseases such as hyperglycemia, in which blood sugar level increases either because of insufficient secretion of insulin by pancreas or diminished response of cells towards insulin. Diabetes is classified into two types, type 1 diabetes and type 2 diabetes. Numerous pathogenic responses play major roles in the development of diabetes [2]. Type 2 diabetes mellitus is characterized by insulin resistance and patients with this type of diabetes require increased secretion of insulin which is unable to fulfill by pancreatic $\beta$-cells due to abnormality in their function. Over $90 \%-95 \%$ of patients had diabetes are type 2 patients and of most of them are adults [3]. Globally, the rapid pervasiveness of type-II DM is becoming a grave medical consideration, demanding the investigation on novel therapeutic agents. Among the major challenging aims of diabetes management, the most important is to normalize the blood glucose levels in patients with diabetes mellitus. Diabetes could potentially be 
prevented or controlled by controlling monosaccharide absorption and the network of carbohydrate degrading enzymes [4]. Two principle digestive enzymes $\alpha$-amylase and $\alpha$ glucosidase are responsible for the degradation of complex dietary carbohydrates into sugar in the digestive tract [5]. Various inhibitors like voglibose, miglitol and acarbose that reduce PPHG by disturbing the action of carbohydrate digesting enzymes thus decreasing the glucose absorption are commonly available in market. These are synthetic drugs and carries many adverse effects including gastrointestinal problems, abdominal discomfort and diarrhea [6] therefore necessitating the demand for novel compounds with no or few side effects. Since, many times plants have been used traditionally to cure diabetes patients. There are several reported antidiabetic properties of medicinal plants till now. It has been reported that plants have also been utilized to treat other related conditions of diabetes including diabetic retinopathy, diabetic peripheral neuropathy etc. But endophytes have not been extensively explored for antidiabetic agents [7]. Exploration of valuable bioactive compounds from microbes is rather easier and inexpensive [8]. Endophytes are endosymbiotic microbes (e.g. bacteria or fungi) as the term "Endophyte" is derived from a combination of two words: Endo- means 'within' and phyte means 'plant' thus these are the microorganisms that inhabit the interstitial spaces of plants or found within plant tissues (stem, roots and leaves), forming symbiotic association with plant and doesn't cause any detrimental effect to host species [9]. Endophytic fungi are promising and plentiful sources of an extensive range of beneficial natural products with varied chemical structures, higher bio diversities and numerous fascinating bioactivities [10]. It is obvious that endophytic fungi have now been identified as a store house of secondary bioactive metabolites such as novel and unique antibiotics, antidiabetic, anticancer, antioxidant and immunosuppressant compounds. So far, more than 2,000 naturallyderived products have been recovered from endophytes found in medicinal plants, including phenol and phenolic acids, isocoumarin derivatives, lactone, polysaccharides, amines and amides, indole derivatives, pyrrolizidine stetralones, xanthones, phenylpropanoids and lignans, benzoquinones, chlorinated metabolites have been reported from fungal endophytes [11]. Although endophytic fungi are a remarkable source of potent and novel secondary metabolites yet they have not been widely characterized, investigated and screened for the exploration of enzyme inhibitors. It has been proposed that different plants are known to produce $\alpha$-amylase and $\alpha$-glucosidase inhibitors but few numbers of reports are found from endophytic microorganisms [12].

Aims and Objectives

By spotting the broad capabilities of endophytic fungi of producing biologically active metabolites, this study was aimed to isolate and evaluate endophytic fungi from different plants like Mango (Mangifera indica), Neem (Azadirachta indica) and jambolan (Syzygium cumini $L$ ) for their antidiabetic potentials. These plants have been used for the treatment of diabetes since many times [13].

\section{Materials and methods Collection of Plant Samples}

Mature and healthy leaves of Azadirachta indica, Syzygium cumini and Mangifera indica were collected from the biopark of Bahauddin Zakariya University of Multan. About 200 grams of healthy and fresh leaves were cut using a sterile cutter and placed in sterile zipper bags. Samples were handled carefully and processed immediately or within 24 hours after collection. Samples were dried properly to remove surface moisture prior to storage. Samples were labeled and tagged and transported to the laboratory in polythene bags 
under sterile conditions. Fungal endophytes were isolated from plants by following the reported methods with slight alterations [14]. The entire framework of our study has been shown in (Figure 1).

\section{Sterilization of plant samples}

The plant materials were placed under running tap water for $2 \mathrm{~min}$ and washed with autoclaved distilled water to remove all the surface debris. Thereafter trimming of leaves was carried out using sterile surgical blades, edges of leaves were removed. Then leaves were transported to laminar flow under aseptic condition where leaves were excised into 6-7 pieces (3-5 $\mathrm{mm}$ size) using sterile cutters. The leaves were completely rinsed with sterile deionized water for $1 \mathrm{~min}$, and then soaked into $70 \%$ ethanol for 1 minute, again treated with sterile distilled water for $30 \mathrm{sec}$ and then washed with $0.05 \%$ mercuric chloride solution for 2 minutes to completely sterilize the surface. Leaves were again soaked in autoclaved deionized $\mathrm{H}_{2} \mathrm{O}$ and dried using sterile filter paper before placing on media plates. Leaves after complete drying were placed on Potato Dextrose Agar (PDA) and Sabouraud Dextrose Agar (SDA) media plates. These media plates were augmented with an amoxicillin $200 \mathrm{mg} / \mathrm{ml}$ as antibiotic to avoid bacterial contamination. Now, the plates were incubated at $25^{\circ} \mathrm{C}$ for $4-8$ days for growth [15].

\section{Isolation of endophytes}

After 3 to 7 days of incubation at $25^{\circ} \mathrm{C}$, the hyphal tips were started emerging from the plant parts indicating the growth of endophytes around leaves. The hyphal tips were removed, disinfected and preserved on media (PDA) plates. The number of fungal colonies was counted. The colonies were subcultured and purified [15].

\section{Morphological characterization}

Morphological characters were studied with the help of microscope. Slides were prepared by adding a drop of deionized water or ethanol on the slide and the culture was taken with the help of forceps from petri plates. These colonies were added on the slides and mixed with the drop of liquid with the help of toothpick and covered with cover slips. Cover slips on slides were fixed with the help of nail paint. Now the arrangement of hyphae, branching configuration and sporulation were observed under microscope. The microscopic images were taken with the help of camera.

Production of anti-diabetic metabolites from endophytes

For primary screening, $50 \mathrm{ml}$ production media, malt extract broth (MEB), containing $3 \%$ malt extract, $0.5 \%$ peptone and dextrose $2 \%$ was prepared in Erlenmeyer flasks (250 $\mathrm{ml})$. A small block of agar (6mm diameter) from PDA plates, containing endophytic fungal hyphae, was removed with the help of a sterile borer or tips and added in the flask containing MEB. Then the flasks were placed in a rotary shaker at 200 revolutions $\min ^{-1}$ for 10 days at $30^{\circ} \mathrm{C}$. After that each flask was supplemented with ethyl acetate $(50 \mathrm{ml})$ and again kept in a shaker at 150 revolutions min $^{-1}$ at $45^{\circ} \mathrm{C}$. After 2-6 hours, supernatant was removed from each flask. The removed supernatants were kept for dryness on Rotaevaporator to get concentrated organic phase [16].

\section{Antidiabetic Assays}

The most commonly used procedure is alphaamylase inhibitory assay. It was carried out by the addition of $200 \mu \mathrm{L}$ of fungal extract $(15 \mathrm{ml})$ that was mixed with $200 \mu \mathrm{L}$ of sodium phosphate buffer $(0.02 \mathrm{M})$ with $6.7 \mathrm{pH}$ carrying $0.5 \mathrm{mg} / \mathrm{ml}$ solution of alpha-amylase. The tubes containing the mixture were incubated for $10 \mathrm{~min}$ at $30^{\circ} \mathrm{C}$ and then $200 \mu \mathrm{L}$ of starch (1\%) solution was added. The reaction mixtures were again incubated at $30^{\circ} \mathrm{C}$ for $10 \mathrm{~min}$. Now to stop the reaction mixture, $500 \mu \mathrm{L}$ of DNS (3, 5-dinitrosalicylic acid) reagent was added. Mixtures in tubes were incubated again for in pre-set water bath at $92^{\circ} \mathrm{C}$ for 5 minutes and thereafter the mixtures in tubes were set to cool at $40^{\circ} \mathrm{C}$. 
After cooling the mixture at room temperature, $6 \mathrm{ml}$ of sterilized deionized water was added in each tube. Absorbance was measured at $540 \mathrm{~nm}$ using spectrophotometer. Acarbose as positive control was taken. Inhibitory activity of alpha-amylase was measured using this formula [17].

$\%$ inhibition $=\left[\left(\mathrm{A}_{\mathrm{c}}-\mathrm{A}_{\mathrm{e}}\right) / \mathrm{Ac}\right] 100$

Where $A_{c}$ represents Absorbance of control and $A_{e}$ represents Absorbance of extract.

\section{Statistical analysis}

The entire data were demonstrated as the mean of triplicate assays and represented as mean \pm standard errors (SEM). Results were analyzed statistically by means of a statistical package Minitab version 17. The significant mean difference between values was analyzed by one-way analysis of variance (ANOVA) then through Tukey's test [18].

\section{Results and discussion}

\section{Collection and isolation of endophytes}

Leaves from three different plants Mango (Mangifera indica), Neem (Azadirachta indica) and jambolan (Syzygium cumini L) were collected for the isolation of endophytic fungi in order to evaluate their ability to produce antidiabetic compounds. A total of 8 fungal endophytes, coded as MPW, MBR, MAN, NGU, NTH, JGY, JGR and JCO were isolated from selected plants (Table 1). These isolated strains were purified and preserved on PDA or SDA plates.

\section{Identification of endophytic fungi}

The sample codes of the selected plants endophytic fungi demonstrated microscopic morphology and characteristic colony that were used to distinguish them from each other. In case of strain MPW, mycelium was hyaline, septate, profusely branched and conidiophores were white. Fungal isolate MBR cultured on PDA medium showed brown to dark brown mycelia. Apparently, the colonies showed rough, hard and whitish surface. The isolate was observed under a microscope, it revealed septate and long hyphae with rounded conidia. Strain MAN was identified as Aspergillus specie demonstrated dark brown, large, globose conidial heads that become radiate. Conidiophores are hyaline, smooth-walled and turned dark towards vesicles. Heads of conidia are biseriate comprising brown phialides. Conidia turned white to dark brown to black, globose to sub-globose and rough walled. Colonies spread rapidly. Characteristics of NGU are white to grey mycelia, thick hyphae, conidia are round to oval without septa (Figure 2).

Fungal isolate NTH cultured on PDA showed white to grey mycelia, flat ledges and dispersal hyphae. Microscopic view of this colony represented rounded conidia and long conidiophores and septate. Mycelia of JGY were green and showed umbrella like colonies, hyphae are septate and thick, highly branched and elongated. Characteristics of JGR demonstrated that the colonies grown on PDA had 20-40 mm diameter, generally plane, velutinous and low, irregularly floccose centrally, slightly granular, mycelium inconspicuous, grey to greenish turquoise. Conidiophores borne surface hyphae, stipes are 250-350 $\mu \mathrm{m}$ long comprising thin smooth walls, low and sometimes moderate production of ellipsoidal to sub-spheroidal conidia, 2-5 $\mu \mathrm{m}$ in length, irregular columns and flat walled, penicillin commonly biverticillate, triverticiallate comprising 1-2 rami, either appressed and terminal of sometimes divergent. Characteristics of JCO demonstrated that colonies grown on PDA plates reached to $40-60 \mathrm{~mm}$ diameter, reversely white centrally or uniform pale, floccose to dense white mycelium, colorless at the borders, septate branched mycelium.

\section{Production of metabolites}

Growth of fungal endophytes and the production of metabolites were observed after 7, 10 and 12 days. Maximum growth and production occurred after 10 days at $30^{\circ} \mathrm{C}$. The broth in each flask has containing the colony of desired cultures. The culture medium and 
mycelia were extracted 3 times with ethyl acetate to achieve the crude extracts. The fungal extracts were concentrated into solid filtrate via Rota evaporator. The concentrated filtrate was used for antidiabetic assay.

\section{Antidiabetic analysis}

Diabetes is one of chronic and serious disorders among various diseases of protein, carbohydrate and fat metabolism, affecting large set of population of the world [19]. In diabetes type II, body continuously produces insulin but it functions improperly because of insulin resistance. Two digestive enzymes alpha amylase and alpha glucosidase are involved in the breakdown of carbohydrates into sugar [19].

Morphologically three endophytic fungi were identified including MAN belong to Aspergillus sp., JGR belong to Penicillium sp., and JCO belong to Alternaria sp., other strains could not be identified that are expected to be unique.

In this study, alpha-amylase inhibitory activities of different endophytic fungi were evaluated. For screening of antidiabetic activity, amylase-assay was performed for 8 strains from 3 different plants, Mangifera indica, Azadirachta indica and Syzygium cumini L. Inhibitory activities were observed using spectrophotometer at $540 \mathrm{~nm}$. Among the selected plants, extract of JCO at $200 \mu \mathrm{g} / \mathrm{mL}$ concentration showed the significant alpha- amylase inhibition of $62 \%$ followed by NTH, NGU, MBR and MAN with the inhibition of 59.51, 51, 49.31 and $49.6 \%$. These results showed that all samples could inhibit the activity of $\alpha$-amylase with different degrees of inhibition (Table 2).

The inhibitory activity showed by endophytic fungi could offer a potent source of regulating hyperglycemia. The inhibitory activity exhibited by endophytic fungal culture could be increased by optimizing and improving various process parameters. The results of spectrophotometer reflected a superb fit between the predicted and observed responses, and suggest that these cultures are appropriate for inhibitor production. Four polypeptide $\alpha$ amylase inhibitors of $14 \mathrm{kDa}$ have been isolated from wheat [20]. Peptide of molecular mass $18 \mathrm{kDa}$ exhibited $\alpha$-amylase inhibitory activity has also been reported from Cladosporium herbarum by Saito 1982. The endophytic fungi from leaves of Mangifera indica, Syzygium cumini (L.) and Azadirachta indica showed inhibitory activity against $\alpha$ amylase enzyme making these endophytes a charming panaroma for diabetes management. Acarbose, are used as standard antidiabetic drugs, isolated from Actinoplanes utahensis [24]. Different screening procedures proved that endophytes are not only antineoplastic, anticancer, antimicrobial [25] but also good alpha amylase and alpha glucosidase inhibitors [26]. Antidiabetic agents from Phoma sp., Aspergillus sp. that are used to lower down blood sugar level known to have constituents of phenol, 2, 6-bis [1,1dimethylethyl]-4-methyl and 2,6-di-tert-butylp-cresol identified by GCMS analysis [27]. An endophytic fungus pseudomassaria $s p$. obtained from African rainforest produces an antidiabetic compound L-783,281 which is insulin mimetic and does not destroy in digestive tract as insulin destroyed in digestive tract [28, 29]. Fungal endophytes isolated from Swietenia macrophylla seeds and the leaves of Cassia siaema were identified to contain inhibitory activity [30]. 

$\left.\mathrm{HgCl}_{2}\right)+$ drying on fliter paper]

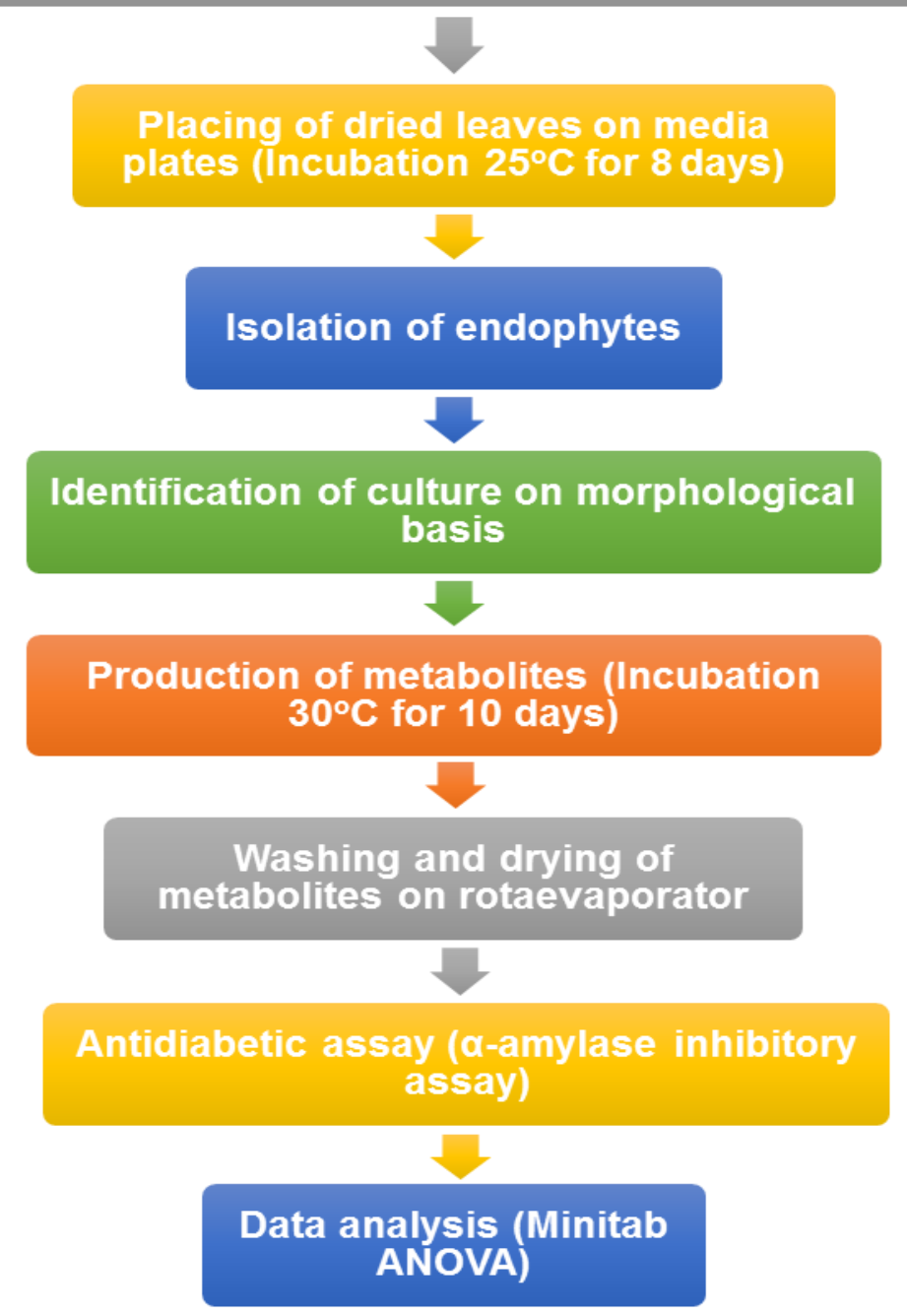

Figure 1. Our framework for studying antidiabetic activity of endophytes

Table 1. Samples isolated from leaves of various plants

\begin{tabular}{|c|c|c|c|}
\hline S. No. & Sample code & Plant & Plants Scientific Name \\
\hline 1 & MBR & Mango & Mangiferaindica \\
\hline 2 & MPW & Mango & Mangiferaindica \\
\hline 3 & MAN & Mango & Mangiferaindica \\
\hline 4 & NGU & Neem & Azadirachtaindica \\
\hline 5 & NTH & Neem & Syzygirachtaindica \\
\hline 6 & JGY & Jambolan & SyzygiumcuminiL. \\
\hline 7 & JGR & Jambolan & SyzygiumcuminiL. \\
\hline 8 & JCO & Jambolan & \\
\hline
\end{tabular}




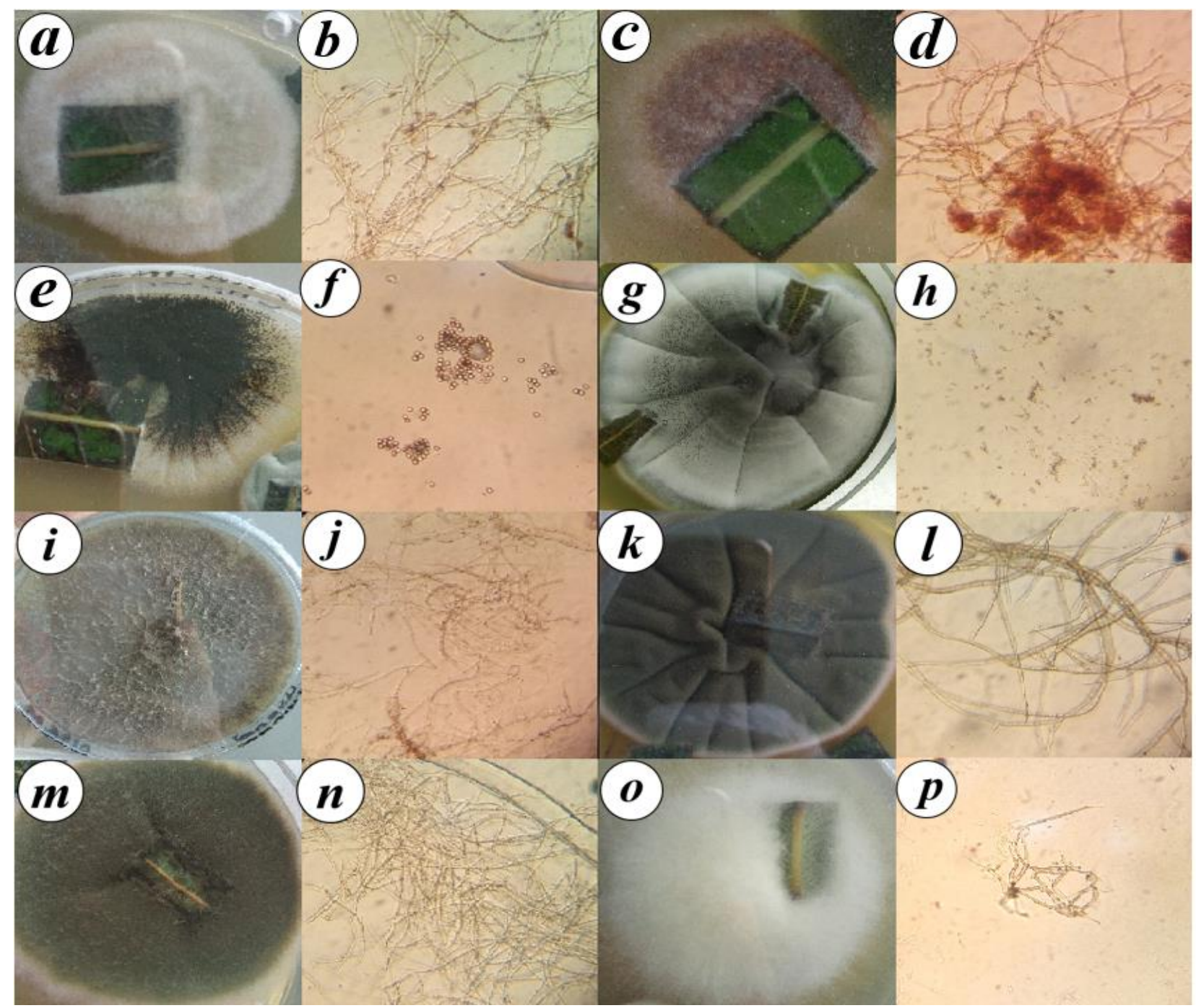

Figure 2. Macroscopic and microscopic morphologies of isolated colonies of endophytic fungi: (a) MPW, (b) Microscopic image, (c) MBR, (d) Microscopic image, (e) MAN, (f) Microscopic image, (g) NGU, (h) Microscopic image, (i) NTH, (j) Microscopic image, (k) JGY, (L) Microscopic image, (M) JGR, (N) Microscopic image, (O) JCO, (P) Microscopic image

Table 2. Percentage of inhibition of alpha-amylase by different endophytic fungi at the concentration of $200 \mu \mathrm{g} / \mathrm{ml}$

\begin{tabular}{|c|c|c|c|}
\hline S. No. & Endophytic fungi & Absorbance & \% of inhibition \\
\hline 1 & MPW & 0.366 & 36 \\
\hline 2 & MBR & 1.004 & 49.31 \\
\hline 3 & MAN & 1.01 & 49.6 \\
\hline 4 & NTH & 0.234 & 59.51 \\
\hline 5 & NGU & 0.279 & 51 \\
\hline 6 & JGY & 0.982 & 45.54 \\
\hline 7 & JGR & 0.659 & 29.62 \\
\hline 8 & JCO & 0.542 & 62 \\
\hline
\end{tabular}




\section{Conclusion}

Diabetes is becoming epidemic in emerging world; around two third individuals living in developing countries are affected from diabetes. This study reveals that endophytic fungi inhibit the activity of alpha-amylase and it is varied with different species of plants. These results suggested that endophytic fungi from plants could be a potential source of developing remarkable antidiabetic drugs. These drugs could control diabetes through inhibiting a major enzyme alpha-amylase that hydrolyzes carbohydrates into sugar.

\section{Authors' contributions}

Conceived and designed the experiments: $\mathrm{R}$ Khan \& SA Muhammad, Performed the experiments: R Khan \& STQ Naqvi, Analysed the data: N Fatima \& SA Muhammad, Contributed materials/ analysis/ tools: STQ Naqvi, Wrote the paper: R Khan \& SA Muhammad

\section{References}

1. Agnaniet H, Mbot EJ, Keita O, Fehrentz JA, Ankli A, Gallud A, Garcia M, GaryBobo M, Lebibi J \& Cresteil T (2016). Antidiabetic potential of two medicinal plants used in Gabonese folk medicine. BMC Complem Alter Med 16(1): 71-78.

2. Bhutkar M \& Bhise $S$ (2012). In vitro assay of alpha amylase inhibitory activity of some indigenous plants. Int J Chem Sci 10(1): 457-462.

3. Halban PA, Polonsky KS, Bowden DW, Hawkins MA, Ling C, Mather KJ, Powers AC, Rhodes CJ, Sussel L \& Weir GC (2014). $\beta$-cell failure in type 2 diabetes: postulated mechanisms and prospects for prevention and treatment. $J$ Clin Endocr Metab 99(6): 1983-1992.

4. Alagesan K, Thennarasu P, Kumar V, Sankarnarayanan S \& Balsamy T (2012). Identification of $\alpha$-glucosidase inhibitors from Psidium guajava leaves and Syzygium cumini Linn. seeds. Int J Pharm Sci Res 3(2): 316-322.

5. Lee B-H, Yan L, Phillips RJ, Reuhs BL, Jones K, Rose DR, Nichols BL, QuezadaCalvillo R, Yoo S-H \& Hamaker BR
(2013). Enzyme-synthesized highly branched maltodextrins have slow glucose generation at the mucosal $\alpha$-glucosidase level and are slowly digestible in vivo. PloS one 8(4): e59745.

6. Ag H (1994). Pharmacology of $\alpha$-glucosidase inhibition. Eur J Clin Invest 24(S3): 3-10.

7. Franco OL, Rigden DJ, Melo FR \& Grossi-de-Sá MF (2002). Plant $\alpha$-amylase inhibitors and their interaction with insect $\alpha$-amylases. Eur J Biochem 269(2): 397412.

8. Nair SS, Kavrekar V \& Mishra A (2013). In vitro studies on alpha amylase and alpha glucosidase inhibitory activities of selected plant extracts. Eur J Exp Biol 3(1): 128132.

9. Ramos S, Silva L, Correia M, Ara, ujo J \& Coelho L (2016). Endophytic microorganisms from Bauhinia monandra leaves: Isolation, antimicrobial activities and interaction with galactose-specific lectin BmoLL. Afr J Microbiol Res 10(17): 600-607.

10. Bhagat J, Kaur A, Sharma M, Saxena A \& Chadha B (2012). Molecular and functional characterization of endophytic fungi from traditional medicinal plants. World $J$ Microbiol Biotechnol 28(3): 963-971.

11. Strobel GA (2003). Endophytes as sources of bioactive products. Microb Infect 5(6): 535-544.

12. Mun'im A, Ramadhan MG \& Soemiati A (2013). Screening of endophytic fungi from Cassia siamea Lamk leaves as aglucosidase inhibitor. Int Res J Pharm 4(5): $128-131$

13. Jaiswal N, Srivastava S, Bhatia V, Mishra A, Sonkar A, Narender T, Srivastava A \& Tamrakar A (2012). Inhibition of AlphaGlucosidase by Acacia niloticaPrevents Hyperglycemia along with Improvement of Diabetic Complications via Aldose Reductase Inhibition. J Diabetes Metab S 6: 004.

14. Fatima N, Mukhtar U, Ihsan-Ul-Haq MAQ, Jadoon M \& Ahmed S (2016). Biological 
Evaluation of Endophytic Fungus Chaetomium sp. NF15 of Justicia adhatoda L.: A Potential Candidate for Drug Discovery. Jundishapur J Microbiol 9(6): e29978.

15. Singh B, Thakur A, Kaur S, Chadha B \& Kaur A (2012). Acetylcholinesterase inhibitory potential and insecticidal activity of an endophytic Alternaria sp. from Ricinus communis. Appl Biochem Biotechnol 168(5): 991-1002.

16. Singh B \& Kaur A (2016). Antidiabetic potential of a peptide isolated from an endophytic Aspergillus awamori. J Appl Microbiol 120(2): 301-311.

17. Kazeem MI, Ogunbiyi JV \& Ashafa A (2013). In vitro Studies on the Inhibition of $\alpha$-Amylase and $\alpha$-Glucosidase by Leaf Extracts of Picralima nitida (Stapf). Trop $J$ Pharm Res 12(5): 719-725.

18. Watcharachaisoponsiri T, Sornchan P, Charoenkiatkul S \& Suttisansanee U (2016). The $\alpha$-glucosidase and $\alpha$-amylase inhibitory activity from different chili pepper extracts. Int Food Res J 23(4): 1439-1445.

19. Surya S, Salam AD, Tomy DV, Carla B, Kumar RA \& Sunil C (2014). Diabetes mellitus and medicinal plasnts-a review. Asian Pac J Trop Dis 4(5): 337-347.

20. Feng GH, Richardson $M$, Chen MS, Kramer KJ, Morgan TD \& Reeck GR (1996). $\alpha$-Amylase inhibitors from wheat: amino acid sequences and patterns of inhibition of insect and human $\alpha$-amylases. Insect Biochem Mol Biol 26(5): 419-426.

21. Yokose K, Ogawa M \& Ogawa K (1984). New. ALPHA.-amylase inhibitor, trestatins. III. Structure determination of new trestatin components Ro 09-0766, Ro 09-0767 and Ro 09-0768. J Antibiot 37(2): 182-186.

22. Truscheit E, Frommer W, Junge B, Müller L, Schmidt DD \& Wingender W (1981). Chemistry and Biochemistry of Microbial
a-Glucosidase Inhibitors. Angew Chem Int Ed Engl 20(9): 744-761.

23. Kameda Y, Asano, Naoki, Yoshikawa, Michiyo, Matsui, Katsuhiko (1980). Valienamine as an. ALPHA.-glucosidase inhibitor. J Antibiot 33(12): 1575-1576.

24. Schmidit D, Frommer W, Junge B, Muller L, Wingender W, Truscheit E \& Schafer D (1977). $\alpha$-Glucosidase inhibitors. Naturwiss 64(10): 535-536.

25. Hong K, Gao A-H, Xie Q-Y, Gao HG, Zhuang L, Lin H-P, Yu H-P, Li J, Yao X-S \& Goodfellow M (2009). Actinomycetes for marine drug discovery isolated from mangrove soils and plants in China. Mar Drugs 7(1): 24-44.

26. Jasmine DJ \& Agastian P (2013). In vitro antioxidant activity and in vivo alpha glucosidase activity of endophytic actinomycetes isolated from Catharanthus roseus (1.) G. Don. J Pharm Res 6(6): 674678.

27. Dhankhar S, Dhankhar S \& Parkash Yadav J (2013). Investigations towards new antidiabetic drugs from fungal endophytes associated with Salvadora oleoides Decne. Med Chem 9(4): 624-632.

28. Zhang B, Salituro G, Szalkowski D, Li Z, Zhang Y, Royo I, Vilella D, Díez MT, Pelaez F \& Ruby C (1999). Discovery of a small molecule insulin mimetic with antidiabetic activity in mice. Sci 284(5416): 974-977.

29. Singh B \& Kaur A (2016). Antidiabetic potential of a peptide isolated from an endophytic Aspergillus awamori. J Appl Microbiol 120(2): 301-311.

30. Ramdanis R, Soemiati A \& Munim A (2012). Isolation and $\alpha$-Glucosidase inhibitory activity of endophytic fungi from mahogany (Swietenia macrophylla King) seeds. Int J Med Aromat Plants 2(3): 447452. 